\title{
Teoria crítica e semiperiferia: Reflexões sobre a modernidade global e a geopolítica da teoria sociológica
}

DOMINGUES, José Maurício. Teoria crítica e (semi) periferia. Belo Horizonte: Editora UFMG, 2011.

\section{Resumo}

Nos últimos anos, sobretudo devido ao destaque que a crítica pós-colonial assumiu no âmbito da sociologia, diversos estudos têm apontado para a necessidade de se problematizarem as relações de produção e circulação da teoria sociológica entre centro e periferia. O livro de José Maurício Domingues, Teoria Crítica e (Semi)Periferia, ao trazer para o centro da reflexão teóricos provenientes de diferentes regiões periféricas do globo - como América Latina, Índia, China e Israel -, abre novas possibilidades para a reflexão crítica sobre a geopolítica da teoria sociológica, assim como contribui para a discussão em torno da modernidade global a partir da periferia e da semi-periferia.

Palavras-chave: Teoria Crítica. Periferia. Teoria Pós-Colonial. Conhecimento. Modernidade.

\footnotetext{
" Doutorando em Sociologia. Professor do Departamento de Ciências Sociais da Universidade Federal de Juiz de Fora (Brasil). E-mail: fperlatto@yahoo.com.br
} 


\section{Critical theory and Semiperiphery: Reflections on global modernity and the geopolitics of sociological theory}

\section{Abstract}

In the past few years, mainly due the prominence that the Post-Colonial studies have assumed in the field of sociology, several studies have pointed to the need to problematize the relations of production and circulation of sociological theory between center and periphery. José Maurício Domigues's book, Theory and Semi-Periphery, by bringing to the center of theoretical reflections authors from different peripheral regions of the globe - such as Latin America, India, China and Israel -, opens new possibilities for critical reflection about the geopolitics of sociological theory as well contributes to the discussion on global modernity from the Periphery and Semi-Periphery.

Keywords: Critical Theory; Periphery; Postcolonial Theory. Knowledge. Modernity.

Um dos tópicos que vem recebendo maior atenção na agenda política e reflexiva das ciências sociais nos últimos anos diz respeito à consolidação dos chamados países emergentes - em especial dos BRICS (Brasil, Rússia, Índia e China) - como novos players da geopolítica mundial. Não à toa, tem sido permanente a reivindicação, por parte destes, de uma participação mais ativa nas instâncias decisórias do poder global, em especial no Conselho de Segurança da Organização das Nações Unidas (ONU) e no Fundo Monetário Internacional (FMI), rompendo com o domínio anacrônico que determinadas potências ainda exercem no âmbito dessas instituições. A crise financeira que sacudiu o mundo em 2008 parece ter intensificado este processo de pressão no sentido do realinhamento do poder global, conferindo aos países periféricos maior margem de manobra para reivindicar participação mais destacada no processo de deliberação das políticas internacionais. 
Seria possível que, ao corroborarmos tal diagnóstico acerca da geopolítica internacional, pudéssemos estender suas assertivas para também pensarmos acerca de uma possível redistribuição da geopolítica do conhecimento em âmbito global? Ou, em outras palavras, é factível imaginarmos que o processo de realinhamento político seja acompanhado e/ ou impulsionado por um movimento de transformação na forma como, historicamente, tem se dado a produção e circulação do conhecimento, de forma geral, e, para entrarmos mais precisamente na seara que nos interessa, da teoria sociológica? A periferia teria a capacidade de produzir uma imaginação sociológica suficientemente autônoma e sofisticada de modo a ser ouvida nos países centrais, rompendo, dessa forma, com a sua histórica dependência da formulação teórica oriunda dos países do Norte, em especial aqueles situados na Europa e os Estados Unidos?

Importa destacar, desde já, que este debate entre o centro e a periferia, no que concerne à geopolítica da teoria sociológica, não é de todo novo no âmbito da disciplina, já possuindo uma história considerável ${ }^{1}$. Contudo, ele acabou por ganhar maior consistência nos últimos anos, sobretudo sob influência daquela produção que ficou comumente conhecida como "crítica pós-colonial", que, não obstante as particularidades dos autores identificados em seu amplo arco, buscou questionar as agendas teóricas produzidas a partir da Europa e dos Estados Unidos, apontando para o fato de elas serem transportadas acriticamente para as periferias, reforçando um processo de dominação metodológica, conceitual e epistemológica ${ }^{2}$. Prova da atualidade desse debate pode ser observada tomando-se como medida sua repercussão recente no âmbito da Global

\footnotetext{
$<?>$ Sobre este ponto, ver Chernilo (2010).

<?> Diversos autores têm sido identificados com o termo "pós-coloniais", como Homi Bhabha, Edward Said, Gayatri Chakravorty Spivak, Stuart Hall e Paul Gilroy, ainda que grande parte deles venha produzindo suas obras a partir do centro. Para um trabalho clássico que procura articular as críticas no sentido acima destacado, ver Connel (2007).
} 
Dialogue, newsletter publicada pela International Sociological Association (ISA), na qual sociólogos como Ülrich Beck (2010), Raewyn Connell (2010) e Sujata Patel (2011) têm enfrentado um embate sobre questões centrais no que tange à produção da teoria sociológica e sua relação entre "centro" e "periferia".

Assim como este debate não é totalmente novo em âmbito mundial, ele também não o é no Brasil. Contudo, é inegável o seu arrefecimento nas últimas décadas, talvez como consequência direta do próprio avanço de um viés antiteórico que tem assolado as ciências sociais brasileiras, pelo menos desde a década de 1970 (Domingues, 2007). É justamente no sentido de buscar reconectar a sociologia brasileira com este debate em torno da geopolítica da teoria sociológica que se podem compreender as reflexões propostas por José Maurício Domingues, em seu novo livro, Teoria crítica e (semi)periferia (Editora UFMG, 2011). Partindo do diagnóstico acerca da debilidade da inserção das nossas ciências sociais nesta geopolítica, o autor convida a uma reflexão teórica mais ampla não somente em torno das complexas relações entre centro e periferia, no que concerne à "produção" e "consumo" da teoria sociológica, mas busca, a partir desta problematização, pensar acerca da modernidade global.

O ponto de partida aqui é a periferia, mas o objetivo geral da reflexão é universal. Busca-se colocar em diálogo periferia e centro, de modo a lançar um olhar analítico mais complexificado em torno da modernidade global em sua atual fase. Para realizar este intuito, Domingues aponta para a necessidade das ciências sociais brasileiras romperem com a hegemonia de uma espécie de nacionalismo metodológico, excessivamente centrado no olhar para dentro, que, sem qualquer pretensão de estabelecer reflexões teóricas mais amplas, acaba por enclausurar a nossa capacidade de alçar vôos imaginativos em pé de igualdade com os sociólogos europeus e norte-americanos. Centrada exclusivamente na compreensão dos nossos 
problemas, a sociologia brasileira teria abdicado de lançar um olhar mais abrangente sobre o mundo, com a consequência de relegar ao centro a tarefa de produzir teoria sobre as questões concernentes à modernidade. O resultado desse processo seria o reforço da dependência das teorias produzidas de fora, as quais seriam apenas aplicadas após importadas como se compram pacotes de inovação tecnológica (p.89).

No sentido de estimular uma reflexão que rompa com este quadro, Domingues propõe uma teoria crítica capaz de combinar, ainda que de forma tensa, a 'crítica imanente', interna à modernidade, por um lado, e a alteridade internalizada, que depende de outras fontes civilizacionais, mas se desdobra nos quadros de uma modernidade complexificada (p.16). Em outras palavras, trata-se de mobilizar a periferia e seus sociólogos para que, em diálogo com as sociologias centrais, se produza uma nova imaginação sobre a própria modernidade global, em sua terceira fase. Avançando em uma reflexão já presente em outros trabalhos (Domingues, 2009), mas que ganha maior sistematicidade no livro ora em análise, Domingues destaca que a atual fase da modernidade, diferentemente das duas primeiras - que se estenderiam do século XIX a 1920, e de 1930 a 1970, centradas, respectivamente, no mercado e no Estado keynesiano -, teria emergido em meados da década de 1990, impulsionada pelo avanço da globalização, sendo marcada por uma "articulação mista", caracterizada por "giros modernizadores" que implicam em um crescimento exponencial da complexidade social em diversas áreas.

Compreender esta terceira fase da modernidade vis a vis as transformações que se processam na periferia é, portanto, a tarefa que Domingues se coloca. Podemos dizer que, para cumprir seu objetivo, o autor busca dialeticamente trazer o debate sobre a modernidade, associado à reflexão em torno daquilo que estamos chamando de geopolítica da teoria sociológica. Isso implica em um esforço no sentido de mobilizar para 
esta reflexão a análise de países periféricos e semiperiféricos, bem como seus autores de referência, pouco conhecidos pelas ciências sociais, de modo geral, e pela sociologia brasileira, em particular. Ainda que alguns recebam uma atenção mais destacada do que outros, é impossível não ressaltar a importância de se trazer para o centro do debate não somente a América Latina - em especial o Brasil e Cuba -, mas Índia, China e Israel. Autores de diversas geografias, portadores de diferentes imaginações sobre o mundo - tais como Gabriel Cohn, Walter Mignolo, Ashis Nandy, Daniel Bell, Shmuel Eisenstadt - são postos para dialogar, com o intuito da produção de uma reflexão mais bem desenhada sobre a terceira fase da modernidade global.

Não temos espaço e nem a pretensão de discutir pormenorizadamente os dez capítulos do livro. Correríamos o risco de simplificar complexas análises sobre a modernidade e seus "giros modernizadores" na América Latina, a produção teórica de Walter Mignolo, a teoria da dominação e da indiferença de Gabriel Cohn, o confucionismo na China a partir das reflexões de Daniel Bell, a sociologia israelense e a crise do consenso sionista, a problematização da Revolução Cubana e de seus desdobramentos, assim como o debate em torno da dependência, do desenvolvimento e do desenvolvimentismo, e problematizações sobre democracia, liberdade e dominação, que ganharam novos contornos no Brasil e nos demais países periféricos nos últimos anos. Nossos objetivos são mais reduzidos. O que nos interessa é tentar compreender o saldo reflexivo e teórico sobre a modernidade e a geopolítica da teoria sociológica que emerge, ao fim e ao cabo, da mobilização para o debate dos casos e autores periféricos e semiperiféricos, realizada por Domingues.

O grande mérito do livro talvez esteja justamente no fato de que, mesmo problematizando, por um lado, a desigualdade da geopolítica da teoria sociológica e, por outro, as limitações de uma teorização mais am- 
pla sobre a modernidade global daí decorrentes, Domingues não resvala em críticas exageradamente radicais sobre a modernidade realizadas por autores identificados com a perspectiva "pós-colonial". Tanto no que se refere à produção da teoria sociológica, quanto no que concerne à reflexão em torno da modernidade, o esforço do autor se dá no sentido de problematizar a imaginação vinda do centro, não para descartá-la, mas para que, em diálogo com ela a partir análise de países periféricos e semiperiféricos, bem como de seus cientistas sociais, se torne possível complexificar esta imaginação. Conforme muito bem destacado pelo autor, não deveria nos importar de onde vêm os elementos imaginários e institucionais que podem energizar as subjetividades que buscam romper com os sistemas de dominação contemporâneos (p.13). O desafio está em como estes elementos, frutos de diferenciados "giros modernizadores", serão mobilizados pela reflexão e pelos atores sociais no sentido de uma democratização política e social mais efetiva no contexto da terceira fase da modernidade global.

Isso não quer dizer que ocorra aqui uma aceitação acrítica da modernidade por parte do autor, como poderiam pensar os arautos da crítica pós-colonial. Pelo contrário. Esta é problematizada justamente por não ter cumprido os potenciais emancipatórios contidos em sua proposta original. Como decorrência do caráter excludente que ela acabou assumindo no decorrer da trajetória das suas três fases, a modernidade se vê diante do desafio de ser inquirida por outras tradições e imaginações - como faz o próprio "pós-colonialismo" -, mas não para denunciá-la in toto - como se ela fosse, como um todo, elemento de dominação -, mas para democratizá-la. A crítica é realizada, dessa maneira, a partir de uma perspectiva dialética, na medida em que é imanente à modernidade, mas mobiliza elementos externos objetivando a sua complexificação. A modernidade é encarada aqui, portanto, como um projeto ainda em aberto, a ser dispu- 
tado pelas forças da contestação, em especial os segmentos subalternos. Estes, em suas lutas emancipatórias, mobilizando valores e discursos da tradição moderna, devem enriquecê-la com outras tradições, em um movimento dialético de memória e criatividade.

Podemos estender esta reflexão de Domingues para pensarmos a geopolítica da teoria sociológica. Colocar em diálogo as formulações sobre a modernidade originadas nos centros com aquelas produzidas nas periferias possibilita não apenas a inclusão de mais alguns casos nacionais para ilustrar a tese geral formulada no "centro", mas abre caminhos para a elaboração de uma reflexão capaz de enriquecer a própria teoria sobre a modernidade como um todo. Nesse sentido, trata-se de criticar tanto a aplicação direta das teorias do norte sobre as experiências periféricas sem quaisquer mediações teóricas, que reforçam essencialismos universalistas e colonialismos intelectuais, quanto os essencialismos nacionalistas característicos de algumas formulações das teorias pós-coloniais, segundo as quais as teorias provenientes do norte seriam naturalmente "imperialistas". O ponto a ser sustentando é aquele segundo o qual a periferia dever ser encarada não apenas como uma mera consumidora das teorias provenientes do centro, mas como um espaço autônomo de produção teórica, que, em diálogo com o as sociologias centrais, seja capaz de participar de maneira mais protagônica na produção e circulação do debate teórico global sobre a modernidade.

Em relação ao livro Teoria crítica e (semi) periferia, convém realizar duas críticas à guisa de conclusão. Em primeiro lugar, no que concerne a uma dimensão propriamente analítica, falta à obra uma discussão mais problematizada sobre a crise econômica que atingiu o mundo em 2008. Ainda que mencionada em algumas ocasiões ao longo do livro, ela poderia ter recebido maior atenção, até mesmo pelo fato de ter, por um lado, apontado para alguns dos limites do capitalismo financeiro, característico 
da terceira fase da modernidade global, e, por outro lado, aberto novos caminhos para uma inserção mais protagônica no cenário mundial dos países periféricos e semiperiféricos. Ainda nesse sentido, os artigos do livro poderiam ter explorado de maneira mais satisfatória a ausência da criatividade das forças de esquerda situadas na periferia, as quais, mesmo diante de um cenário favorável para o avanço das lutas emancipatórias, se encontram diante de uma dualidade acrítica paralisante: ou o fetichismo da sociedade civil como fonte da resolução de todos os problemas ou um estatismo militante, que, não obstante lograr sucesso no sentido de superar os impasses do neoliberalismo, oferece rebaixadas possibilidades para uma democratização política e social mais efetiva da sociedade.

Já no que tange à temática da geopolítica da teoria sociológica - ponto nodal do argumento do autor -, talvez tenha faltado uma análise mais detida nas razões pelas quais as relações nesse campo permanecem tão desiguais, para além de um desinteresse crescente entre os sociólogos brasileiros para se engajarem nos debates de escopo global. As reflexões de Renato Ortiz (2008), por exemplo, ainda que não esgotem o tema, têm aberto caminhos importantes para este questionamento, ao destacar a posição hegemônica do inglês na produção científica, de forma geral, e das ciências sociais, de forma particular. No caso mais específico da reflexão sociológica, a produção em língua inglesa acaba adquirindo a capacidade de "guiar" o debate intelectual em escala global, definindo a agenda intelectual e estabelecendo quais temas e questões são mais relevantes de serem problematizadas, com todas as consequências daí advindas para a produção e circulação do conhecimento sociológico entre centro e periferia ${ }^{3}$.

\footnotetext{
${ }^{3}$ Convém destacar, no que tange a este aspecto, que mais recentemente, a International Sociological Association (ISA) vem abrindo caminhos para modificar este quadro de hegemonia do inglês na circulação do conhecimento sociológico. A newsletter Global Dialogue tem sido publicada simultaneamente em diferentes idiomas.
} 
Essas ponderações, contudo, não devem servir para reduzir a importância desse novo livro de José Maurício Domingues. Este trabalho já teria seus méritos somente por possibilitar aos leitores brasileiros o acesso a uma bibliografia ainda muito pouco conhecida acerca de países periféricos e semiperiféricos, abrindo, por conseguinte, um novo campo de investigação. Mas sua vitalidade advém, sobretudo, da sua perspectiva analítica e normativa que, ao chamar a atenção para as desigualdades existentes na produção da geopolítica da teoria sociológica, propõe uma visão descentrada da terceira fase da modernidade global. Ao contrário de certo diagnóstico, segundo o qual não se produz teoria social relevante no país (Costa, 2010), o livro de Domingues comprova que possuímos uma imaginação neste campo bem solidificada e amadurecida, com totais condições de participar mais ativamente dos debates teóricos em âmbito global.

\section{Referências}

BECK, Ulrich. Kiss the frog: The cosmopolitan turn in Sociology. Global Dialogue, International Sociological Association, v. 1, n. 2, November, p. 1-2, 2010.

CHERNILO, Daniel. Nacionalismo y cosmopolitismo: ensayos sociologicos. Santiago: Ed. Universidad Diego Portales, 2010.

CONNELL, Raewyn. Southern theory: the global dynamics of knowledge in social science. Cambridge: Polity Press, 2007.

CONNELL, Raewyn. How can we weave a world Sociology?. Global Dialogue. International Sociological Association. v. 1, n. 2, November, p. 1-2, 2010.

COSTA, Sergio. Teoria por adição. In: MARTINS, Heloisa H. T. S. (Org.). Horizontes das Ciências Sociais: Sociologia. São Paulo: ANPOCS, 2010, p. 25-51.

DOMINGUES, José Maurício. Aproximações à América Latina: desafios contemporâneos. Rio de Janeiro: Civilização Brasileira, 2007.

DOMINGUES, José Maurício. A América Latina e a modernidade contemporânea. Uma interpretação sociológica. Belo Horizonte: Editora UFMG, 2009.

DOMINGUES, José Maurício. Teoria crítica e (semi) periferia. Belo Horizonte: Editora UFMG, 2011. 
PATEL, Sujata. An international Sociology with diverse epistemes. Global Dialogue. International Sociological Association. v. 1, n. 4, February, p. 12-13, 2011.

ORTIZ, Renato. A diversidade dos sotaques: o inglês e as ciências sociais. São Paulo: Brasiliense, 2008.

Recebido em: 14/03/2012

Aceite final: 14/05/2012 